\title{
Antiplatelet agents in perioperative noncardiac surgeries: to maintain or to suspend?
}

This article was published in the following Dove Press journal:

Therapeutics and Clinical Risk Management

Juliana Maria Dantas

Mendonça Borges ${ }^{1,2, *}$

Fernanda Oliveira de

Carvalho ${ }^{1, *}$

Isla Alcântara Gomes ${ }^{3, *}$

Mario Borges Rosa ${ }^{4, *}$

Antonio Carlos Sobral

Sousa ${ }^{1, *}$

'Nucleus of Post-Graduation in Health Sciences, Federal University of Sergipe, São Cristóvão, Brazil;

${ }^{2}$ Nucleus of Pharmacy, Tiradentes

University, Aracaju, Brazil; ${ }^{3}$ Nucleus

of Post-Graduation in Pharmaceutical

Sciences, Federal University of

Sergipe, São Cristóvão, Brazil;

${ }^{4}$ Institute for Safe Practice in Drug

Use, Belo Horizonte, Brazil

*These authors contributed equally to this work
Correspondence: Juliana Maria Dantas Mendonça Borges

Federal University of Sergipe,

Av Prof Marechal Rondon, s/n Jardim

Rosa Elze, CEP49.100-000 São Cristovão,

Sergipe, Brazil

Tel +55 79999829326

Email jumariapharma@gmail.com
Background: When prescribing antiplatelet agents, physicians face the challenge of protecting patients from thromboembolic events without inducing bleeding damage. However, especially in the perioperative period, the use of these medications requires a carefully balanced assessment of their risks and benefits.

Objective: To conduct a systematic review to check whether the antiplatelet agent is to be maintained or suspended in the perioperative period of noncardiac surgeries.

Search strategy: A comprehensive literature search using Science Direct, Scopus, MEDLINEPubMed, and Web of Science was undertaken.

Selection criteria: Clinical trials of noncardiac surgeries with patients taking regular antiplatelet therapy, published between 2013 and 2018.

Results: A total of 1,302 studies were initially identified, with only four meeting the inclusion criteria. The selected studies were conducted in different countries such as, including India (2), Serbia (1), and the USA (1). The age group was similar in all studies, from 61 to 75 years. The most frequent surgery was related to tooth extraction and transurethral resection of bladder cancer. There was a group of patients who used single antiplatelet agents and groups who used single therapy and double therapy. Acetylsalicylic acid was the common drug in all studies.

Conclusion: It was concluded that the clinical trials were classified as good quality and that it was not necessary to suspend antiplatelet therapy prior to surgical procedures such as dental extraction and transurethral resection of bladder cancer. It should be noted that it is necessary to jointly evaluate the type of antiplatelet agent, the thrombotic risk of the patient, and the hemorrhagic risk of the surgical procedure.

Keywords: platelet aggregation inhibitors, antiplatelet agent, surgery, systematic review

\section{Introduction}

Cardiovascular diseases (CVD) are the leading cause of premature morbidity and mortality in the world, with accelerated growth in developing countries. ${ }^{1-3}$ It is believed that by 2020 , more than $80 \%$ of CVD will occur in low- and middle-income countries. ${ }^{4}$ Major cardiovascular complications (acute myocardial infarction - AMI - nonfatal, cardiac arrest, and cardiovascular death) during the perioperative period have been observed, which are also strongly associated with mortality at 30 days after a noncardiac surgical procedure..$^{5-9}$

In 2014, Botto et $\mathrm{al}^{10}$ affirmed that cardiac complications are the main cause of postoperative death in patients undergoing noncardiac surgeries, and millions of patients with high cardiovascular risk are subjected annually to these types of surgeries. ${ }^{1-13}$ Parallel to this, the use of antiplatelet agents for secondary prevention of cardio- and cerebrovascular diseases has increased considerably. ${ }^{14}$ 
While providing protection ischemic, antiplatelet drugs expose patients to a degree of risk of bleeding, ${ }^{15-17}$ a justification that leads many surgeons to recommend to patients the interruption of these medications preoperatively. On the other hand, the withdrawal of the antiplatelet agent in the perioperative period may be associated with mortal thrombotic complications. ${ }^{16,18,19}$

Thus, surgeons are frequently confronted with decisionmaking on whether or not to discontinue antiplatelet therapy during the perioperative period for noncardiac surgeries, ${ }^{15,17,20}$ because they must take into account the potential protective effect of antiplatelet therapy vs the risk of bleeding caused by these drugs ${ }^{15,17}$ so, there is no unanimous opinion among medical professionals, regardless of whether the patient's use of antiplatelets is intended for primary or secondary prevention of cardiovascular events. ${ }^{20,21}$

The present systematic review is justified by the perspective of helping surgeons, mainly, in the decision-making regarding the dilemma of maintaining or not the antiplatelet agents in the perioperative period of noncardiac surgeries. Thus, its main objective is to conclude, through clinical trials, whether the antiplatelet agents should be maintained or suspended in the perioperative period of noncardiac surgeries.

\section{Methods}

This study was conducted following the Preferred Reporting Items for Systematic Reviews and Meta-Analyses statement and supplemented by guidance from the Cochrane Collaboration Handbook. A protocol of this systematic review was designed a priori and was registered in the PROSPERO database (registration number 93420).

\section{Search strategy}

Four databases (Internet sources) were used to search for appropriate papers that fulfilled the purpose of this study. Those included the National Library of Medicine (MEDLINE-PubMed), Science Direct, Web of Science, and Scopus, using different combinations of the following keywords: "platelet aggregation inhibitors," "antiplatelet agent," "clinical trial," "surgery." The databases were searched for studies conducted from January 2013 to February 2018. The research strategy was designed to identify studies on patients undergoing noncardiac surgeries who regularly use antiplatelet agents. Citations were manually limited to clinical trials of noncardiac surgeries. Additional papers were included in our study after analyses of all references from the selected articles. We did not contact the investigators nor did we try to identify unpublished data.

\section{Study selection}

All electronic search titles, selected abstracts, and full-text articles were independently reviewed by a minimum of two reviewers (JMDM and FOC). Disagreements over inclusion/ exclusion criteria were resolved by reaching a consensus. The following inclusion criteria were applied: clinical trials, human studies, noncardiac surgeries, regular use of antiplatelet agents, and studies between 2013 and 2018. Studies were excluded according to the following exclusion criteria: studies that did not fit the above characteristics, review articles, meta-analyses, abstracts, conference proceedings, editorials/letters, and case reports (Table 1).

\section{Data extraction and risk of bias assessment}

Data were extracted by one reviewer using standardized forms and were checked by a second reviewer. The following information was extracted from all studies: population (n) of each study, average age (in years), type of surgery, use of antiplatelet agents (the studies did not indicate how many days the patients had to interrupt the therapy with the antiplatelet agent before the surgeries), results, limitations of the study, and conclusions.

We assessed the risk of bias according to the Cochrane guidelines for randomized controlled trials. We assessed seven domains for evaluation: sequence generation and allocation concealment (selection bias), blinding of participants and personnel (performance bias), blinding of outcome assessment (detection bias), incomplete outcome data (attrition bias), selective outcome reporting (reporting bias), and other potential sources of bias. We rated the risk of bias as low, unclear, or high according to established criteria. And the total score was obtained by assigning 1 point for each "low" answer and 0 points for "unclear" or "high" answers, for a total quality score ranging from 0 to 7 . A study was considered with low quality when $<2$ of 7 items were met. Two investigators independently (JMDM and FOC) conducted this assessment, and any disagreements were resolved by consensus.

\section{Results \\ Selection of studies}

The process followed for article selection is presented in Figure 1. We found 804 studies on Science Direct, 8 on the Scopus, 294 on the Web of Science, and 196 on PubMed, so a total of 1,302 articles were identified. After rejecting 


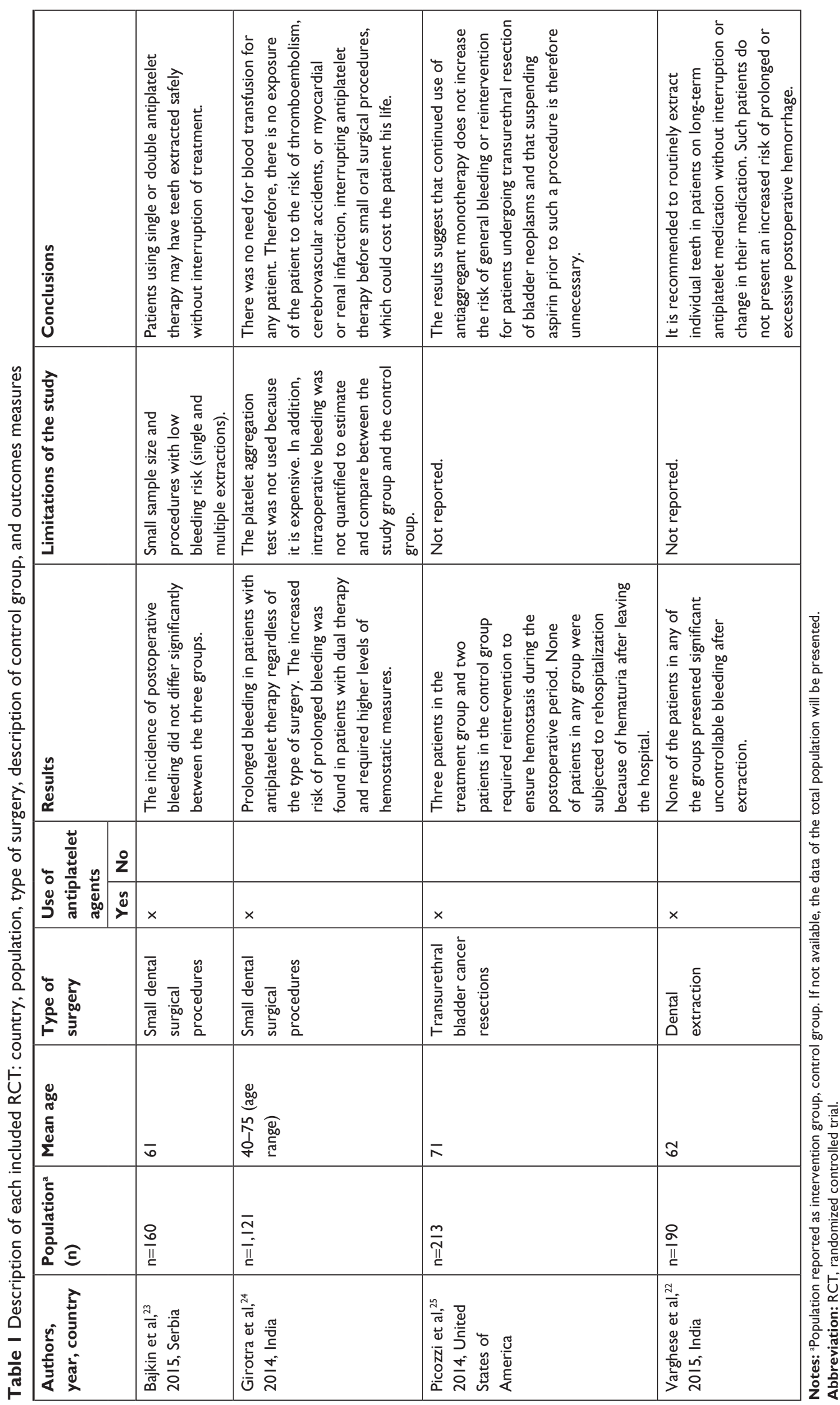




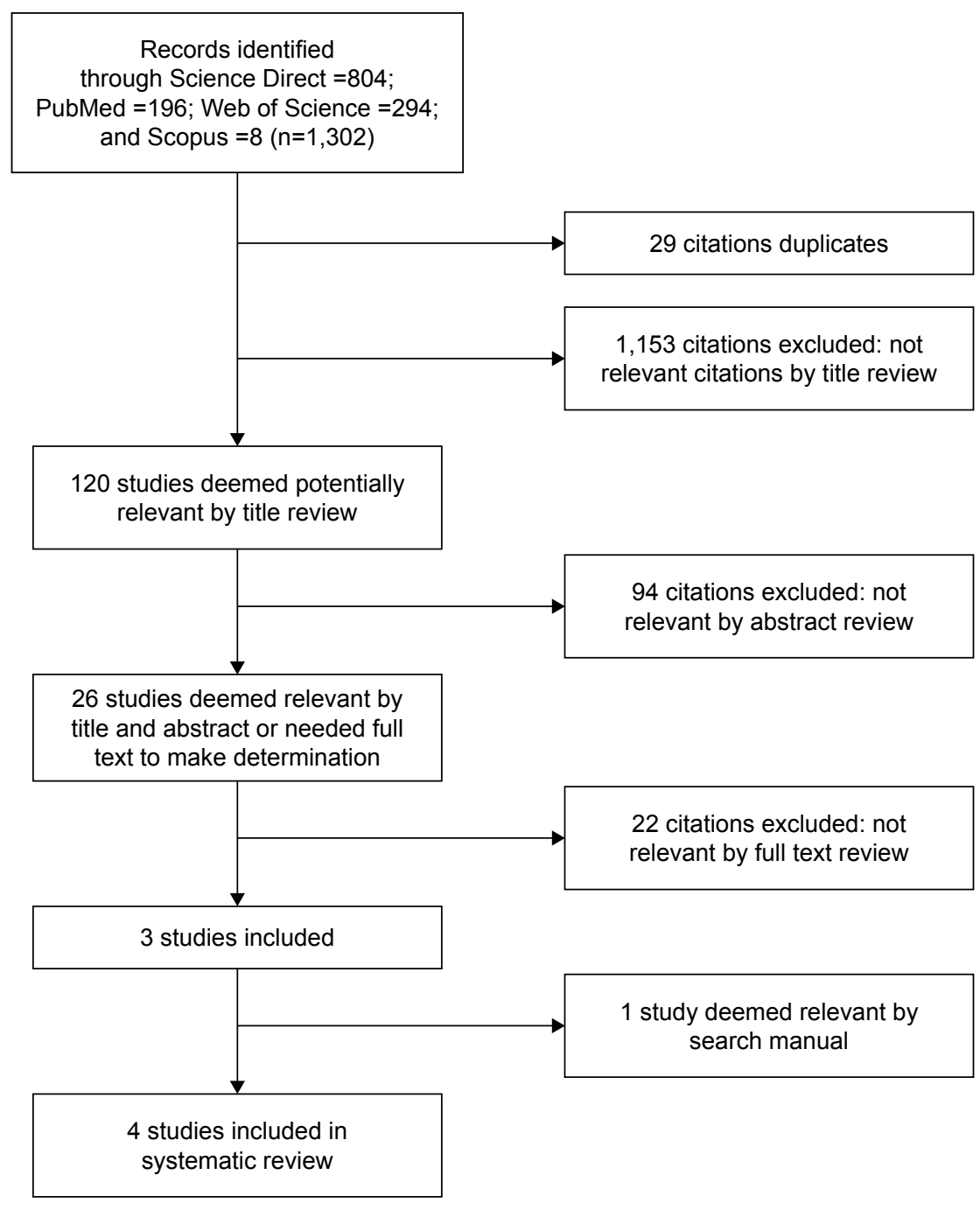

Figure I Flow diagram for literature searching and screening.

duplicate articles, we proceeded with the reading of 1,273 titles and abstracts. Finally, 26 articles were selected for full reading. After the assessment of and rejection of articles not shown in full, duplicates, letters to the reader, case studies, articles published before the year 2013, articles that were not in English, Spanish, or Portuguese, or those whose theme did not include the approach of this study, three articles remained. At the end, we added one article found on manual searching of the literature, and so four remaining articles were finally selected (Figure 1). There was a high level of agreement on inclusion/exclusion between the two investigators who screened the retrieved articles $(\kappa$ index $>88 \%$ ).

\section{Characteristics of included studies}

The selected studies were conducted in different countries such as India (2), Serbia (1), and the USA (1). They were published between the years 2013 and 2015 (Table 1).
The sample size of each study varied a little: there was an article covering 160 patients to one study with 1,121 patients, but the age group was similar in all studies, from 61 to 75 years. The most frequent surgery was related to tooth extraction ${ }^{22-24}$ and transurethral resection of bladder cancer. ${ }^{25}$ Acetylsalicylic acid (ASA) was the common drug in all studies.

In a study performed in the United States, ${ }^{25}$ transfusion support was required during four transurethral resection procedures of bladder cancer performed in patients who used antiplatelet therapy in the perioperative period and during two procedures for the control group $(P=0.242)$. In another study ${ }^{22}$ carried out in India, none of the patients subjected to dental extraction had uncontrollable bleeding after the procedure, a result seen both in the group that used interrupted antiplatelet therapy and in the group that had the therapy 5 days before the surgical procedure. In both studies, no cardiac events or complications related to anesthesia occurred in the evaluated patients nor was there a need to rehospitalize any of them. 
In the studies comparing the occurrence and/or level of bleeding after surgical procedures of patients on dual-platelet antiplatelet therapy and those on single therapy, the case of a patient who used concomitant ASA and clopidogrel daily (nonsuspended) for the surgical procedure and after tooth extraction, presented mild bleeding easily controlled by local hemostasis. ${ }^{23}$ Another study ${ }^{24}$ showed that the risk of prolonged bleeding in the postoperative dental period was higher for patients who used double antiplatelet therapy; however, with hemostatic measures, bleeding was easily controlled, without the need for blood transfusion.

In the four studies selected, only one study, ${ }^{25}$ which dealt with transurethral bladder cancer resection procedures, mentioned that patients who maintained antiplatelet therapy were previously evaluated by a urologist, surgeon, anesthesiologist, and cardiologist before undergoing the surgical procedure.

Regarding the limitations of the studies, they were not reported in two of them, ${ }^{22,25}$ however, the study carried out in $\mathrm{Serbia}^{23}$ pointed out as limitations, the fact that the sample is small, and the surgical procedures performed are low risk of bleeding (single and multiple dental extractions). On the other hand, the study carried out in India by Girotra et $\mathrm{al}^{24}$ determined as a limitation the fact that the platelet aggregation test was not used because it was very expressive, as well as the nonquantification of intraoperative bleeding to estimate and compare blood loss between the study group and control group.

\section{Risk of bias}

Figure 2 provides a summary of the bias risk of the four studies. Only one study was adequate for random sequence generation, the other three presented a risk of uncertain bias because they did not inform the randomization process; one study had a high risk of allocation concealment (selection bias) and another three presented a risk of uncertain bias; The four studies presented a risk of uncertain bias in relation to the blindness of participants and professionals. In the case of risk of blindness in the evaluation of the results, all studies presented a risk of uncertain bias in the outcome evaluation reported by the patient, and only one study presented a low risk of blindness bias in the objective outcome evaluation, two other studies presented a risk of bias uncertain for the same assessment, and the fourth study had a high risk of bias. All the clinical trials cited here presented a low risk of incomplete outcomes and of a selective outcome. In addition, all the tests were included in the criteria adopted by these authors of quality score of at least two points and could be classified as being of good quality.

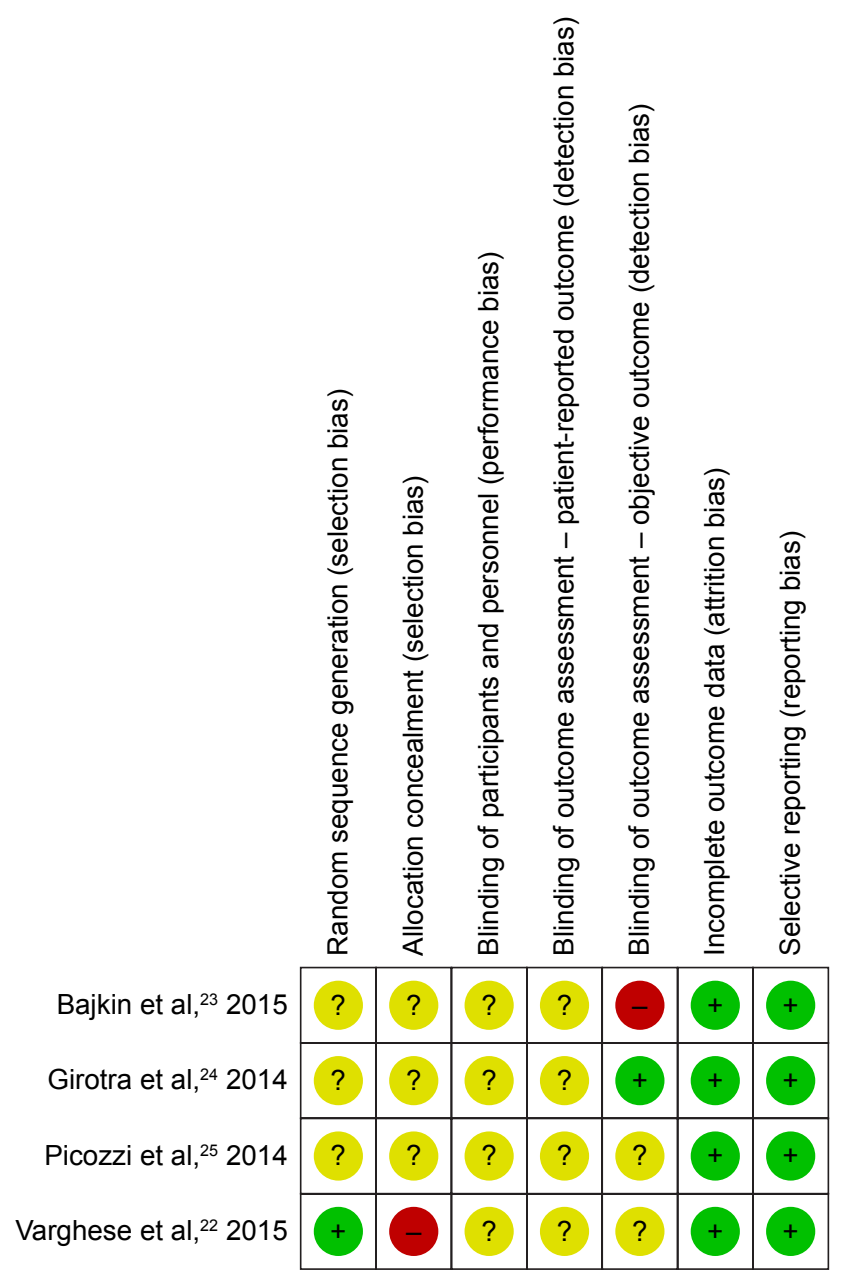

Figure 2 Summary of the bias risk of the four studies.

Notes: +: low risk of bias; -: high risk of bias; ?: uncertain risk of bias.

\section{Discussion}

In contemporary surgical practice, the management of platelet antiaggregation therapy is a fundamental condition. ${ }^{26,27}$ In our review, we selected four clinical trials from different countries dealing with the subject, two of which were from India, probably because in the past 50 years several epidemiological studies have been available that define the prevalence of CVD, in which more recent data show that this is the leading cause of death in the Indian population, followed by diseases such as asthma, diarrhea, perinatal diseases, and respiratory infections. ${ }^{28,29}$ In addition, studies evaluating the use of ASA and clopidogrel in this population have also been observed, ${ }^{30}$ as it is currently considered that the Indian pharmaceutical field is the third largest with regard to the volume of antiplatelet agents. ${ }^{31}$

One of the clinical trials analyzed in our review was conducted in the United States, probably because almost a third of the North American population uses ASA, which is a cause for concern for physicians, because parallel to this there was 
also the increase in the number of noncardiac surgeries undergone by these patients in this country. ${ }^{14,20,26,32}$ The other and last clinical trial was carried out in Serbia, a finding that can be understood by the results of the EPICOR study published in $2012,{ }^{33}$ which sought to identify regional differences in the use of antiplatelet agents for the treatment of acute coronary syndrome and showed that North and South Europe represent more expressive consumption of these drugs than countries of Eastern Europe and Latin America.

Regarding the type of surgical procedure, we observed a higher prevalence of dental extractive surgery in both clinical trials conducted in India and in Serbia, as well as performed in elderly patients, the predominant age group in our study. These findings can be understood by the fact that India has 76 million elderly people and, along with the rapid aging of the population, there have been a number of difficulties in terms of general and oral health. ${ }^{34-36}$ Accordingly, the need for dental extractions as preventive and curative measures for several diseases, among them caries, a disease that affects the majority of adults in most industrialized countries according to the World Health Organization (2000), ${ }^{37}$ and oral cancer, leads India to have the highest index in the world. ${ }^{34}$ Oral health care is also an important activity in Serbia, where dental health care has a long tradition. ${ }^{38}$ Serbia began to develop after the Second World War intensively and extensively. ${ }^{39}$ In 2010 , of 5 million visits to the public dental service in Serbia, more than 700 thousand were referrals for surgeries for dental extraction. ${ }^{40}$

The other type of surgical procedure described in this review was conducted in the United States and refers to urologic surgery of the transurethral resection type of bladder cancer, probably because bladder cancer accounts for about 14,000 cancer-related deaths among men in this country, with almost 60,000 new cases diagnosed each year. ${ }^{41}$ In addition, the antiplatelet agents aspirin and clopidogrel, as well as the nonsteroidal anti-inflammatory drugs are the drugs most used by the North American population. ${ }^{42}$

In addition to the increase in the number of noncardiac surgical procedures, the number of patients adding risk factors for CVD is increasing with the indication of using antiplatelet agents continuously. These two situations contribute to clinicians, surgeons and anesthesiologists often finding themselves in the dilemma between maintaining or suspending these drugs in the preoperative period. Decisionmaking in this context involves analysis of the different types of risks (thrombosis and bleeding) and, therefore, should be based on the best evidence available. ${ }^{21}$
In our systematic review, the four selected clinical trials evaluated the risk of perioperative bleeding with ASA or clopidogrel alone, and one of them also evaluated the use of ticoplidina; ${ }^{23}$ two of them also assessed the risk of bleeding with dual antiaggregation therapies (aspirin + clopidogrel, aspirin + ticlopidine, and aspirin + prasugrel). ${ }^{22,23}$ In all the trials, it was concluded that there is no need to suspend the medications prior to procedures such as dental extraction and transurethral resection of the bladder, because according to these studies there is no need to expose the patient to the risk of thromboembolism, cerebrovascular accidents or AMI interrupting the platelet antiaggregation therapy prior to small surgical procedures..$^{22-25}$

In agreement with the findings of this review, the American College of Physicians of the Thorax and the Brazilian Society of Cardiology argue that patients who use ASA for secondary prevention and who will undergo noncardiac surgical procedures must continue it in use. ${ }^{43-45}$ This was confirmed in other studies, which revealed that there was no significant difference in the occurrence of bleeding events, ${ }^{46,47}$ even among those using dual antiplatelet therapy, ${ }^{48}$ when the platelet antiaggregant(s) is/are maintained in the perioperative period.

However, the Guidelines of the European Society of Cardiology, published in 2014, argue that the maintenance of aspirin in the perioperative period increases the risk of hemorrhagic complications by $50 \%$ and may need to be discontinued for more than 7 days before certain ophthalmologic, neurological, or spinal surgeries. However, in individuals at risk for CVD, nonadherence or withdrawal of ASA tripled the risk of a major adverse cardiovascular event. Thus, these guidelines conclude that the use of low-dose ASA before noncardiac surgeries should be individualized, balancing perioperative bleeding and thrombotic risk against cardiovascular benefit. ${ }^{13}$

Also, the American Society's recommendations are that it is not beneficial to initiate or continue the use of ASA prior to noncardiac surgeries in patients with no history of coronary stenting unless the risk of ischemic events outweighs the risk of surgical bleeding. ${ }^{19,49}$ In a randomized multicenter international study conducted between 2010 and 2013, involving 135 hospitals from 23 different countries, totaling more than 10,000 patients, it was concluded that the use of ASA in the preoperative period of noncardiac surgeries and immediately in the postoperative period does not have a significant effect on the prevention of cardiac complications and even nonfatal AMI, but it considerably increases the risk of bleeding in this period. ${ }^{26}$ 
In many of these studies, including the guidelines themselves from different countries, medical procedures are not specified by type of noncardiac surgical procedure to which the patient will be subjected. Thus, the information is more generalized, with the exception of neurological surgeries and transurethral prostatectomies, since the literature is unanimous in stating that even if the patient is using aspirin and/or clopidogrel for secondary prevention, they must be suspended for 7 days before the procedure, since the occurrence of bleeding in these types of procedures can be fatal. ${ }^{44}$

Based on the results of that review, compared with the findings of other studies, it is understood that the maintenance of antiplatelet therapy in perioperative of noncardiac surgery should be based on the type of medicine, the surgical risk, and the thrombotic risk of each patient. The guidelines of the Brazilian Society of Cardiology for a patient who makes continuous use of clopidogrel for secondary prevention is that the risk of bleeding from the type of surgery should be considered. Thus, when the risk of bleeding is moderate or high, clopidogrel should be discontinued before the procedure, and when the risk is low the antiaggregant should be maintained in the perioperative period. ${ }^{44,50} \mathrm{With}$ a more robust analysis, as advocated by the authors of this review, the Consensus Guide "Perioperative management of the patient receiving antiplatelet" of Anesthesiology Portuguese Society takes into account both the antiplatelet that the patient is in use as well as the hemorrhagic risk of surgery, and also the thrombotic risk of each patient. ${ }^{50}$

In this sense, considering that tooth extraction surgeries present in this review are considered to be of low hemorrhagic risk, as stated in the SPA Consensus Guide (2014), ${ }^{52}$ antiplatelets alone or in double therapies should not be suspended - a result proven in clinical trials. ${ }^{22-24}$ However, despite the fact that urological surgeries are of high hemorrhagic risk, which was the subject of a study by Picozzi et al, ${ }^{25}$ it was confirmed in this trial that transfusion support was required during four procedures performed on patients taking platelet antiaggregation therapy and during two procedures in the control group $(P=0.242)$; also, no cardiac events nor complications related to anesthesia occurred. Three patients in the treatment group and two patients in the control group required reintervention to ensure hemostasis during the postoperative period. However, none of the patients in any group were rehospitalized for hematuria after leaving the hospital, and it was concluded that continued use of antiplatelet monotherapy does not increase the risk of general bleeding or reintervention for patients undergo- ing transurethral resection neoplasms of the bladder and that suspending aspirin prior to such procedure is therefore unnecessary.

Finally, we believe that this systematic review constitutes a valuable addition to the research and practice in health interventions regarding the prescription of antiplatelet drugs in surgeries, since our findings provide a basis for the surgeon, the dental surgeon, the anesthesiologist, and the cardiologist to make decisions on the prescription of antiplatelet agents in the perioperative period of small noncardiac surgeries, and thus ensure patient safety regarding the prevention of thrombotic and hemorrhagic events. However, although the trials included in this review were considered to be of good quality and thus corroborated for the construction of other studies, all trials presented a risk of uncertain bias in some of the criteria analyzed, and two of the trials had high risk of bias, ${ }^{22,23}$ which serves as an alert for other studies that are developed in this line to have these criteria very well defined in its description.

\section{Conclusion}

It is unnecessary to compromise the patient's life by subjecting him/her to the risk of thromboembolism, stroke, or AMI due to the suspension of antiplatelet therapy before surgical procedures such as dental extraction and transurethral resection of bladder cancer. These were the main findings of our review, which involved four clinical trials, classified as good quality, and corroborated with the results of other types of studies available in the literature. However, we note that further studies involving other types of surgeries are necessary, and that determinations regarding the prescribing of antiplatelet in the perioperative period of noncardiac surgeries should be based on the type of antiplatelet agent, the thrombotic risk of the patient, and the hemorrhagic risk of the surgical procedure.

\section{Disclosure}

The authors report no conflicts of interest in this work.

\section{References}

1. Mansur AP, Favarato D. Mortality due to cardiovascular diseases in Brazil and in the metropolitan region of São Paulo: a 2011 update. Arq Bras Cardiol. 2012;99(2):755-761. [Article in English, Portuguese].

2. Mathers CD, Loncar D. Projections of global mortality and burden of disease from 2002 to 2030. PLoS Med. 2006;3(11):e442.

3. Mansur AP, Favarato D, Souza MF, et al. Trends in death from circulatory diseases in Brazil between 1979 and 1996. Arq Bras Cardiol. 2001;76(6):504-510. [Article in English, Portuguese].

4. Murray CJ, Lopez AD. Global mortality, disability, and the contribution of risk factors: Global Burden of Disease Study. Lancet. 1997; 349(9063):1436-1442. 
5. Writing Committee for the VISION Study Investigators, Devereaux PJ, Biccard BM, et al. Association of Postoperative High-Sensitivity Troponin Levels With Myocardial Injury and 30-Day Mortality Among Patients Undergoing Noncardiac Surgery. JAMA. 2017;317(16): 1642-1651.

6. Ekeloef S, Alamili M, Devereaux PJ, Gögenur I. Troponin elevations after non-cardiac, non-vascular surgery are predictive of major adverse cardiac events and mortality: a systematic review and meta-analysis. Br J Anaesth. 2016;117(5):559-568.

7. van Waes JA, Nathoe HM, de Graaff JC, et al. Myocardial injury after noncardiac surgery and its association with short-term mortality. Circulation. 2013;127(23):2264-2271.

8. Vascular Events In Noncardiac Surgery Patients Cohort Evaluation (VISION) Study Investigators, Devereaux PJ, Chan MT, AlonsoCoello P, et al. Association between postoperative troponin levels and 30-day mortality among patients undergoing noncardiac surgery. JAMA. 2012;307(21):2295-2304.

9. Devereaux PJ, Xavier D, Pogue J, et al. Characteristics and short-term prognosis of perioperative myocardial infarction in patients undergoing noncardiac surgery: a cohort study. Ann Intern Med. 2011; 154(8):523-528.

10. Botto F, Alonso-Coello P, Chan MT, et al. Myocardial injury after noncardiac surgery: a large, international, prospective cohort study establishing diagnostic criteria, characteristics, predictors, and 30-day outcomes. Anesthesiology. 2014;120(3):564-578.

11. Pearse RM, Moreno RP, Bauer P, et al. Mortality after surgery in Europe: a 7 day cohort study. Lancet. 2012;380(9847):1059-1065.

12. Weiser TG, Regenbogen SE, Thompson KD, et al. An estimation of the global volume of surgery: a modelling strategy based on available data. Lancet. 2008;372(9633):139-144.

13. Kristensen SD, Knuuti J, Saraste A, et al. 2014 ESC/ESA Guidelines on non-cardiac surgery: cardiovascular assessment and management: The Joint Task Force on non-cardiac surgery: cardiovascular assessment and management of the European Society of Cardiology (ESC) and the European Society of Anaesthesiology (ESA). Eur Heart J. 2014;35(35):2383-2431.

14. Wiviott SD, Braunwald E, Mccabe CH, et al. Prasugrel versus clopidogrel in patients with acute coronary syndromes. $N$ Engl $J$ Med. 2007;357(20):2001-2015

15. Eikelboom JW, Hirsh J, Spencer FA, Baglin TP, Weitz JI. Antiplatelet drugs: Antithrombotic Therapy and Prevention of Thrombosis, 9th ed: American College of Chest Physicians Evidence-Based Clinical Practice Guidelines. Chest. 2012;141(2 Suppl):e89S-e119S.

16. Artang R, Dieter RS. Analysis of 36 reported cases of late thrombosis in drug-eluting stents placed in coronary arteries. Am J Cardiol. 2007; 99(8):1039-1043.

17. Antithrombotic Trialists' (ATT) Collaboration, Baigent C, Blackwell L, Collins R, et al. Aspirin in the primary and secondary prevention of vascular disease: collaborative meta-analysis of individual participant data from randomised trials. Lancet. 2009;373(9678):1849-1860.

18. Gerstein NS, Schulman PM, Gerstein WH, Petersen TR, Tawil I. Should more patients continue aspirin therapy perioperatively?: clinical impact of aspirin withdrawal syndrome. Ann Surg. 2012;255(5):811-819.

19. Burger W, Chemnitius JM, Kneissl GD, Rücker G. Low-dose aspirin for secondary cardiovascular prevention - cardiovascular risks after its perioperative withdrawal versus bleeding risks with its continuation review and meta-analysis. J Intern Med. 2005;257(5):399-414.

20. Columbo JA, Lambour AJ, Sundling RA, et al. A Meta-analysis of the Impact of Aspirin, Clopidogrel, and Dual Antiplatelet Therapy on Bleeding Complications in Noncardiac Surgery. Ann Surg. 2018;267(1): $1-10$.

21. Magarão RVQ, Marques AC, Feitosa-Filho GS. Aspirina no perioperatório de cirurgias não cardíacas: o dilema entre manter ou suspender* [Aspirin in the perioperative period of non-cardiac surgeries: the dilemma between maintaining or suspending]. Rev Bras Clin Med. São Paulo. 2011;9(3): 218-224. Portuguese.
22. Varghese KG, Manoharan S, Sadhanandan M. Evaluation of bleeding following dental extraction in patients on long-term antiplatelet therapy: A clinical trial. Indian J Dent Res. 2015;26(3):252-255.

23. Bajkin BV, Urosevic IM, Stankov KM, Petrovic BB, Bajkin IA. Dental extractions and risk of bleeding in patients taking single and dual antiplatelet treatment. Br J Oral Maxillofac Surg. 2015;53(1): $39-43$.

24. Girotra C, Padhye M, Mandlik G, et al. Assessment of the risk of haemorrhage and its control following minor oral surgical procedures in patients on anti-platelet therapy: a prospective study. Int J Oral Maxillofac Surg. 2014;43(1):99-106.

25. Picozzi S, Marenghi C, Ricci C, et al. Risks and complications of transurethral resection of bladder tumor among patients taking antiplatelet agents for cardiovascular disease. Surg Endosc. 2014;28(1): 116-121.

26. Devereaux PJ, Mrkobrada M, Sessler DI, et al. Aspirin in patients undergoing noncardiac surgery. N Engl J Med. 2014;370(16):1494-1503.

27. Stone DH, Goodney PP, Schanzer A, et al. Clopidogrel is not associated with major bleeding complications during peripheral arterial surgery. J Vasc Surg. 2011;54(3):779-784.

28. Gupta R, Guptha S, Sharma KK, Gupta A, Deedwania P. Regional variations in cardiovascular risk factors in India: India heart watch. World J Cardiol. 2012;4(4):112-120.

29. Gupta R, Joshi P, Mohan V, Reddy KS, Yusuf S. Epidemiology and causation of coronary heart disease and stroke in India. Heart. 2008; 94(1):16-26.

30. Guha S, Sardar P, Guha P, et al. Dual antiplatelet drug resistance in patients with acute coronary syndrome. Indian Heart J. 2009;61(1):68-73.

31. Rashmi A, Nerlekar S, Rajeev K. Study of variation in prices of oral antiplatelet drugs available in Indian market. Int J Basic Clin Pharmacol. 2016;5(3):810-813.

32. Cannon CP, Harrington RA, James S, et al. Comparison of ticagrelor with clopidogrel in patients with a planned invasive strategy for acute coronary syndromes (PLATO): a randomised double-blind study. Lancet. 2010;375(9711):283-293.

33. Bueno H, Storey RF, Danchin N, et al. Current regional differences in the use of antiplatelet drugs for the treatment of acute coronary syndromes. Results from the EPICOR study. Presented at: European Society of Cardiology (ESC) Congress 2012; August 25-29, 2012; Munich, Germany.

34. Panchbhai AS. Oral health care needs in the dependant elderly in India. Indian J Palliat Care. 2012;18(1):19-26.

35. Chandra S, Chandra S. Text Book of Community Dentistry. 1st ed. New Delhi: Jaypee Brothers Medical Publishers (P) Ltd India. Geriatric Dental Health Care; 2004:239-251.

36. Henry RG, Ceridan B. Delivering dental care to nursing home and homebound patients. Dent Clin North Am. 1994;38(3):537-551.

37. World Health Organization. WHO Global Oral Health Data Bank and WHO Oral Health Country/Area Profile Program. Geneva: World Health Organization; 2000.

38. Andelski H, Obradovic M, Golijanin M. History of Dentistry. Pancevo, Serbia: School of Dental Medicine; 2011.

39. Andelski H, Timotic B. Systems for the provision of oral health care in the Black Sea countries. Part 11: Serbia. Oral Health Dent Manag. 2012;11(2):51-56.

40. Institute of Public Health of Serbia (IPHS). Statistical Yearbook of Health in the Republic of Serbia. Belgrade, Serbia: IPHS; 2010. Available from: http://www.batut.org.rs/index.php?content=77. Accessed March 1, 2018.

41. Siegel RL, Miller KD, Jemal A. Cancer statistics, 2015. CA Cancer J Clin. 2015;65(1):5-29.

42. Kanakadandi V, Parasa S, Sihn P, et al. Patterns of antiplatelet agent use in the US. Endosc Int Open. 2015;3(03):E173-E178.

43. Lorga Filho AM, et al. Brazilian guidelines on platelet antiaggregants and anticoagulants in cardiology. Arq Bras Cardiol.2013;101(3 Suppl): $1-95$. 
44. Douketis JD, Spyropoulos AC, Spencer FA, et al. Perioperative management of antithrombotic therapy: Antithrombotic Therapy and Prevention of Thrombosis, 9th ed: American College of Chest Physicians Evidence-Based Clinical Practice Guidelines. Chest. 2012;141(2 Suppl): e326S-e350S.

45. Oscarsson A, Gupta A, Fredrikson M, et al. To continue or discontinue aspirin in the perioperative period: a randomized, controlled clinical trial. Br J Anaesth. 2010;104(3):305-312.

46. Joseph B, Rawashdeh B, Aziz H, et al. An acute care surgery dilemma: emergent laparoscopic cholecystectomy in patients on aspirin therapy. Am J Surg. 2015;209(4):689-694.

47. Wolf AM, Pucci MJ, Gabale SD, et al. Safety of perioperative aspirin therapy in pancreatic operations. Surgery. 2014;155(1):39-46.

48. Gu Q, Dillon CF, Eberhardt MS, Wright JD, Burt VL. Preventive Aspirin and Other Antiplatelet Medication Use Among U.S. Adults Aged $\geq 40$ Years: Data from the National Health and Nutrition Examination Survey, 2011-2012. Public Health Rep. 2015;130(6):643-654.
49. Fleisher LA, Fleischmann KE, Auerbach AD, et al. 2014 ACC/AHA guideline on perioperative cardiovascular evaluation and management of patients undergoing noncardiac surgery: a report of the American College of Cardiology/American Heart Association Task Force on practice guidelines. J Am Coll Cardiol. 2014;64(22):e77-e137.

50. Portuguese Anesthesiology Society. Manuseio peri-operatorio does doentes medicados com anticoagulantes e antiagegantes plaquetarios: resultado da $3^{\mathrm{a}}$ reuniao de consenso da Sociedade Portuguesa de Anestesiologia [Peri-operative management of the patient medicated with antiplatelet agents: results of the 3 rd consensus meeting of the Portuguese Society of Anesthesiology]. Rev Soc Port Anestesiol. 2014;23(3):76-93. Portuguese.

\section{Publish your work in this journal}

Therapeutics and Clinical Risk Management is an international, peerreviewed journal of clinical therapeutics and risk management, focusing on concise rapid reporting of clinical studies in all therapeutic areas outcomes, safety, and programs for the effective, safe, and sustained use of medicines. This journal is indexed on PubMed Central, CAS,

\section{Dovepress}

EMBase, Scopus and the Elsevier Bibliographic databases. The manuscript management system is completely online and includes a very quick and fair peer-review system, which is all easy to use. Visit http://www.dovepress.com/testimonials.php to read real quotes from published authors.

Submit your manuscript here: http://www.dovepress.com/therapeutics-and-clinical-risk-management-journal 